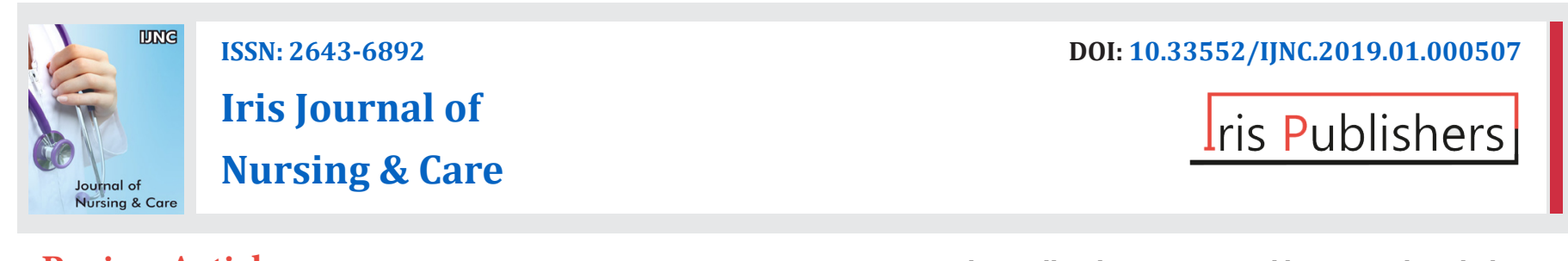

Review Article

Copyright (C) All rights are reserved by Anaiz Ahmed Khowja

\title{
Turnover Propensity among Nurses in Pakistan: Overview and Management
}

\author{
Anaiz A Khowaja ${ }^{1}$, Nasreen Rafiq ${ }^{2}$, Fazal Rabi ${ }^{3}$, Nazia Merchant ${ }^{5}$, Neelam Rafiq ${ }^{4}$ and Sanam Zulfiqar ${ }^{6}$ \\ ${ }^{1}$ Head Nurse at Coronary Care Unit in the Aga Khan University Hospital, Pakistan \\ ${ }^{2}$ Registered Nurse at Internal Medicine, Intensive care unit at The Aga Khan University Hospital, Pakistan \\ ${ }^{3,5}$ Assistant manager clinical affair department at the Indus Hospital, Pakistan \\ ${ }^{4}$ Working at Recep Tayyip Erdogan Hospital, Pakistan \\ ${ }^{6}$ Registered Nurse at Emergency Department in the Aga Khan University Hospital, Pakistan
}

*Corresponding author: Anaiz Ahmed Khowja, Head Nurse at Coronary Care Unit

in the Aga Khan University Hospital, Karachi, Pakistan.

Received Date: January 16, 2019

Published Date: February 01, 2019

\begin{abstract}
Human resource management is an important stake of health care systems. Today, the increase in the burden of diseases has increased the demands of health care professionals in particular Nurses who are the key assets to these agencies. Unfortunately, there is a huge difference between the numbers of nurses between developed and developing countries. Various databases were used to identify this gap, rationales behind its existence and recommendations to improve it.
\end{abstract}

Keywords: Turnover Propensity; Stereotyping; Stigmatized; Vulnerability; Catastrophic; Monopsony; Monopsonist

\section{Introduction}

With increased requirement of health care services, the demand of healthcare providing staff has also increased including doctors, nurses and paramedics staff. Globally 50\%of health care work force includes nurses and midwives, yet there is a shortage in health work force. According to an estimate by WHO, the world still needs about 9 million more nurses and midwives by the year 2030, to attain the sustainable development goal of health and wellbeing [1].

Pakistan's population in 2017 is over 207.7 million, making it the world's sixth-most-populated country (11). It has total 919 hospitals, 560 RHC and 5334 BHU where 33,427 nurses, 23427 midwives and 96000 LHWs. It has all the physical facilities to cater the need of the country. However, the problem lies in the proper utilization and institutional capacity of the nursing and paramedics in the country, to ensure desired outcomes. It is in the middle of epidemiological transition where almost $40 \%$ of total burden of disease (BOD) is accounted for by infectious/communicable diseases [2].

\section{Rational}

Pakistan is one of the 57 countries that have been categorized as shortage of human resource for health [3]. As the growth of the healthcare industry continues, the supply of nurses is depleting. And this shortage has served as major obstacles to sustainability of nursing profession. It hence has become very important to not just find out the factors which lead to this shortage of nurses, but also the necessary measures that need to be taken to prevent this continuous unavailability of nurses in the world and more specifically in low- and middle-income countries. Since, these are countries which are badly struck with communicable and noncommunicable diseases. the aim of the study is to identify the factors that contribute towards insufficient health care providers in the developing countries such as Pakistan. moreover, the study will help discover methods to overcome this shortage.

\section{Methodology}

Database searches of the science direct, Google scholar, pub med, Elsevier, Wiley and CINAHIL with word searches engine "Nursing" 
AND "Economics", "brain drain And Nursing", "Nursing And HRH", "Nursing and Turnover", "Health work force AND Pakistan. In which 20-25 articles were reviewed and cited.

\section{Findings}

Human resource management is an important stake of any health system, where nurses play important role as an asset to the Health care agencies. Unfortunately, there is a big gap of shortage of nurses between Developed and Developing Countries. If we look at the Developed country like USA, its total population is $322,267,564$, making it the third most populous country in the world having 3.1 million RNs, which shows that there are 10 nurses per 1,000 population [4,5]. Nurses are the backbone of healthcare delivery services, but world is experiencing the extreme decline in nursing professionals. In 2008, the U.S. was short of 116,000 nurses. That is predicted to worsen to 500,000 by 2025 . U.S. will need to educate about 1 million new nurses by 2016--which is $40 \%$ the size of today's nursing workforce. The U.S. Department of Labor has predicted that the number of nurses needed in the workforce will grow by 587,000 to 3.1 million nurses by 2016 --a $23 \%$ increase in the number of nurses. In both the US and Canada, 5-6\% of nurses are men and remaining $94 \%$ are females [6].

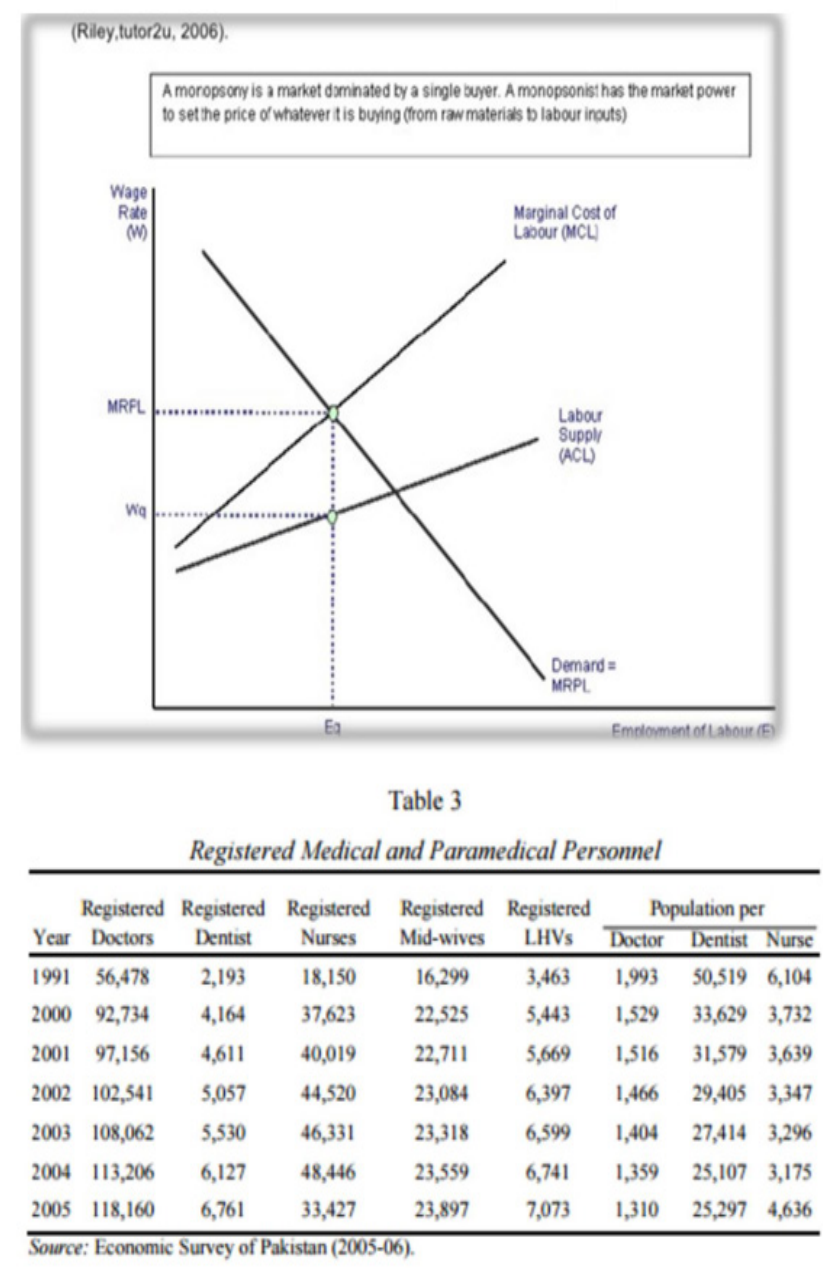

The situation of Nursing is worse in the developing country like Pakistan. We are having 33,427 nurses 23427. The existing nursepatient ratio is approximately 1:50 whereas PNC's prescribed ratio is 1:10 in general areas and 2:1 in specialized areas, which is much less than what WHO is recommended (5:1) [7]. The government of Pakistan report indicates that we are lacking 60,000 nurses. Moreover, for past many years nursing profession mainly belongs to the women. Men comprise only about 6\% nurse working in U.S because of Gender based stereotyping is a common problem in the nursing profession [7].

R. J. Meadus and J. C. Twomey shared number of experiences of men and women in nursing profession that a man is stigmatized to be a nurse as society perceived it as a female profession [8]. While in Pakistan there is no specific ratio was found between male to female. However, in one of tertiary care hospital data; it could be inferred that, the male to female ratio observed in a BScN classroom is 10:90, in ratio of 1:10[9]. Furthermore, Nurses are exposed with various types of individuals and situations in their working conditions, which increase their vulnerability of harassment with increasing age [10].

\section{Discussion}

\section{Human Resource}

For decades, nurses are providing their services immensely in the field of health care. As time has passed the demand for nurses and paramedics staff has increased due to increased demand of the health care. This amplified demand from the system which has created a less number of availability of human resource in the field. In today's world nurses are required to work in the hospital as inpatient setting, in nursing homes, at community levels as community health nurse, in educating and advancement in research in their field. These in response double the demand of nurses in developing countries like Pakistan.

As very well explained in one of the blogs on nurse's shortage that "Shortage of nursing is not just a governmental challenge or a topic for financial analysis; it has a catastrophic impact on health care" [11]. A study in the current issue of Policy, Politics \& Nursing Practice reveals that an estimated 17.5 percent of newly-licensed RNs leave their first nursing job within the first year, and one in three (33.5\%) leave within two years [12]. The researchers found that turnover for this group is lower at hospitals than at other health care settings. It is reported that in Pakistan, number of nurses is low due to their migration to abroad for better job prospects [12]. It is associated with factors such as work place challenges, identification of career priorities, reduced job satisfaction and current work experiences [13]. In one of the articles it is presented that turnover rates in private hospitals of Pakistan have remained above 30\% [14].

\section{Job dissatisfaction}

Job satisfaction is the key to full fill one's role and responsibilities towards the organization. Particularly in nursing, job dissatisfaction occurs due to factors like poor salaries, poor working conditions, no fringe benefits, job insecurity, nepotism, political influences, lack of training opportunities and improper career development structure are the notable factors which hinder the qualified nurses to join public sector [15]. Ayub further illustrated that job dissatisfaction results in absenteeism, turnover in an organization and poor work delivery [10]. A Meta-analysis on motivation for nurses discovered that there are five classes of factors which may be determinants for motivating nursing workforce; work-place characteristics, working 
conditions, personal characteristics, individual priorities, and internal psychological states.

\section{Harassment and stigma to the occupation:}

For past many years, nursing profession mainly belongs to the women. Where Men in the profession comprise only about $6 \%$ of working in U.S [7].

Gender based stereotyping is a common problem in the nursing profession. R. J. Meadus and J. C. Twomey shared number of experiences of men and women in nursing profession that a man is stigmatized to be a nurse as society perceived it as a female profession. Also, they are utilized for the work which requires lifting and shifting jobs due to their manly hood perceived status. Whereas on the other hand, female Nurses are exposed to work with different kind of colleagues and patient in different situation, which makes their working condition more vulnerable and exposed to harassment [16]. Though co-workers and physicians are mostly involved in sexual harassment, still a large percentage is generated by the patients and their attendants [17]. The victim is not the individual only but the organization too. Quality of service will be impacted in organization if its employees are not satisfied and feel unsafe in the work environment. Hence their job performance will decline and will subsequently, damages the reputation of an organization and result in poor delivery of health care system [10].

\section{Monopsony}

Shortage in terms of economics can be defined in term of the amount of demand by the market is greater than the amount supplied in the market which is unable to fulfill the demand and leads to market failure(18).Nurses market works in a similar manner to a labor market where there is a continuous need of the demand but supply is inadequate level to the market. One possible explanation of nurse's shortage is Monopsony in the market. Monopsony means a single buyer with multiple sellers in the market (19). The monopsonist has the power over the prize through controlling the quantity of the service or goods. In nursing, hospitals buy services of the nurses. Hence, the wages could be derived down by hospitals as clearly explained in the diagram 1.1, which in return cause students less likely to be attracted towards this profession.

\section{Conclusion / Recommendation}

In a nut shell, nursing is the main skeleton of any Health care organization, and without any work force it's very difficult to achieve the standards of care. The under wage not only give the demotivation to the personals associated with the profession, but also hinders the new students to opt for the profession. Moreover, the stress and associated stigma to the profession is another hindrance to selecting nursing as a profession. Furthermore, the associated pull factors from the other countries lead the finest nurses of the profession to migrate to other countries, leading to the brain drain to the country. To alleviate this calamity, Government tried best to overcome deficiencies and took necessary steps to upgrade nurses training and advance nursing services. For this reason, Pakistan Nursing Council (PNC) was established and recommended a standardized curriculum for nurses throughout the country [2].
Few of the other recommendations are as follow. Increases the work force of nurses in health care system through stabilizing new schools and motivating students to this profession,

1. Making jobs more attractive and magnetic to nursing candidates

\section{Need to promote RESEARCH in this field}

3. Effective Implementation of Policy

4. Need to provide standardized incentives

Nursing could be finest positioned to influence the future shape of health care, if it would be promoted and given respect within the society.

\section{Acknowledgement}

None.

\section{Conflict of Interest}

No conflict of interest.

\section{References}

1. World Health Organization (2018) Nursing and Midwifey [Fact sheet].

2. pc.gov.pk/mtdf/7-Health/7-Health.pdf.

3. Hafeez A, Khan Z, Bile K, Jooma R, Sheikh M (2010) Pakistan human resources for health assessment. Eastern Mediterranean Health Journal 16 Suppl:145-151.

4. The US nursing workforce: Trends in supply and education (2013).

5. Janiszewski Goodin H (2003) The nursing shortage in the United States of America: an integrative review of the literature. Journal of advanced nursing 43(4): 335-343.

6. Vahey DC, Aiken LH, Sloane DM, Clarke SP, Vargas D (2004) Nurse burnout and patient satisfaction. Medical care 42(2 Suppl): II57-1166.

7. http://www.truthaboutnursing.org/faq/nursing_shortage. html\#ixzz415CrPTVj.

8. Meadus RJ, Twomey JC (2011) Men student nurses: The nursing education experience. Nursing Forum 46(4): 269-279.

9. (2014) Nursing in Pakistan: Handle with care By Nisma Chauhan Arif Soomro.

10. Naveed A, Tharani A, Alwani N (2010) Sexual harassment at work place: are you safe? Journal of Ayub Medical College 22(3): 222-224.

11. Government of Pakistan Ministry of Statistics (2017).

12. Hamid S, Malik AU, Kamran I, Ramzan M (2014) Job satisfaction among nurses working in the private and public sectors: a qualitative study in tertiary care hospitals in Pakistan. Journal of multidisciplinary healthcare 7: 25-35.

13. Hayes LJ, O Brien-Pallas L, Duffield C, Shamian J, Buchan J, et al. (2012) Nurse turnover: a literature review-an update. International journal of nursing studies 49(7): 887-905.

14. Khowaja K, Merchant RJ, Hirani D (2005) Registered nurses' perception of work satisfaction at a Tertiary Care University Hospital. Journal of nursing management 13(1): 32-39.

15. Bahalkani HA, Kumar R, Lakho AR, Mahar B, Mazhar SB, et al. (2011) Job satisfaction in nurses working in tertiary level health care settings of Islamabad, Pakistan. Journal of Ayub Medical College Abbottabad 23(3): 130-133.

16. Meadus RJ, Twomey JC (2007) Men in nursing: making the right choice. Canadian nurse 103(2):13-16. 
17. Dowd S, Davidhizar R (2003) Sexuality, sexual harassment, and sexual humor: Guidelines for the workplace in health care. The health care manager22(2): 144-151.
18. Miller T, Charles A (2015) Goldman Lindsay Butterfield Diana Lavery.

19. Boal WM, Ransom MR (1997) Monopsony in the labor market. Journal of Economic Literature 35(1): 86-112. 